\author{
MUDANÇA NA COBERTURA VEGETAL DO MUNICÍPIO DE BREJO (MA): \\ uma análise a partir do cálculo do Índice de Vegetação por Diferença Normalizada \\ (NDVI)
}

\author{
CHANGE IN VEGETATION COVER IN THE CITY OF BREJO (MA): \\ an analysis based on the calculation of the Normalized Difference Vegetation Index \\ (NDVI) \\ Richard Oliveira Jardim ${ }^{1}$ \\ Universidade Federal do Maranhão \\ richardjardim@hotmail.com
}

\title{
Resumo
}

\begin{abstract}
A inserção do agronegócio na microrregião de Chapadinha (MA), desde final do século XX aos dias atuais, tem (re) configurado o espaço agrário da região. Levando em consideração que a expansão do agronegócio pela sojicultura no município de Brejo no intervalo de tempo entre 2003 e 2010 foi a maior dentre os municípios que compõem a microrregião, este trabalho aponta as transformações ocorridas na cobertura vegetal do município por meio do cálculo do Índice de Vegetação por Diferença Normalizada (NDVI). Para a realização do trabalho, foram utilizadas imagens de satélites Landsat5 para cálculo do NDVI. Como resultado da pesquisa, foi apontado como ocorreu o processo de expansão agrícola e consequentemente o desmatamento da vegetação nativa.
\end{abstract}

Palavras-chave

Índice de Vegetação por Diferença Normalizada; Cobertura vegetal; Sojicultura.

\begin{abstract}
The insertion of agribusiness in the micro-region of Chapadinha (MA), from the end of the 20th century to the present day, (re) configured the region's agrarian space. Considering that the soybean production in the municipality of Brejo was the highest among the municipalities that make up the microregion in the period between 2003 and 2010, this work points out the transformations that occurred in the municipality's vegetation cover through the calculation of the Normalized Difference Vegetation Index (NDVI). In order to do this, satellite images from Landsat5 were used to calculate the NDVI and then analyze agricultural expansion. With the result of the investigation, it was laid out how the agricultural expansion process and, consequently, the deforestation of native vegetation occurred.
\end{abstract}

Keywords

Normalized Difference Vegetation Index; Vegetation cover; Soybean Cultivation.

\footnotetext{
${ }^{1}$ Mestrando do Programa de Pós-Graduação em Geografia pela Universidade Federal do Maranhão e bolsista pela Fundação de Amparo à Pesquisa e ao Desenvolvimento Científico e Tecnológico do Maranhão. ORCid: https://orcid.org/0000-0003-3993-3329.
}

AO CITAR ESTE TRABALHO, UTILIZAR A SEGUINTE REFERÊNCIA:

JARDIM, Richard Oliveira. Mudança da cobertura vegetal do município de Brejo (MA): uma análise a partir do cálculo do Índice de Vegetação por diferença normalizada (NDVI). Revista Ensaios de Geografia. Niterói, vol. 7, nº 14, pp. 147-162, maio-agosto de 2021.

Submissão em: 03/02/2021. Aceito em: 28/04/2021.

ISSN: $2316-8544$

(cc) BY

Este trabalho está licenciado com uma licença Creative Commons 


\section{Ensaios de Geografia}

Essays of Geography | POSGEO-UFF

Introdução

A expansão da sojicultura no estado do Maranhão tem ganhado força desde a última década do século XX. Inicialmente, a produção de soja no estado concentrava-se na mesorregião Sul se expandindo para outras regiões, como é o caso da microrregião de Chapadinha, que ainda na década de 1990 iniciou as primeiras tentativas, mas apenas na década seguinte obteve valores mais expressivos na produção do grão (CARNEIRO $e t$ al., 2008).

Na microrregião de Chapadinha foi possível notar significativas mudanças na configuração espacial de seus municípios, tendo extensas áreas de chapadas sido ocupadas pelo agronegócio, tanto pelo cultivo do eucalipto quanto pelo cultivo da soja.

Entre os municípios dessa microrregião, (Chapadinha, Brejo, Buriti, Anapurus, Mata Roma e Milagres do Maranhão), Brejo ganha destaque na produção do grão de soja, liderando em quantidade de toneladas produzidas (CARNEIRO et al., 2008).

O município de Brejo está localizado na mesorregião leste maranhense, mais precisamente na microrregião de Chapadinha, fazendo limite ao norte com o município de Milagres do Maranhão e São Pedro dos Crentes, a oeste com o município de Mata Roma e Anapurus, ao sul com o município de Buriti e a Leste com o município de Matias Olímpio e Porto, ambos no estado do Piauí. O núcleo urbano do município está sob as coordenadas Latitude $3^{\circ} 39^{\prime} 59.47^{\prime \prime S}$ e Longitude 4247'25.32"O (Figura 1).

Figura 1 - Mapa de localização do município de Brejo (MA) 


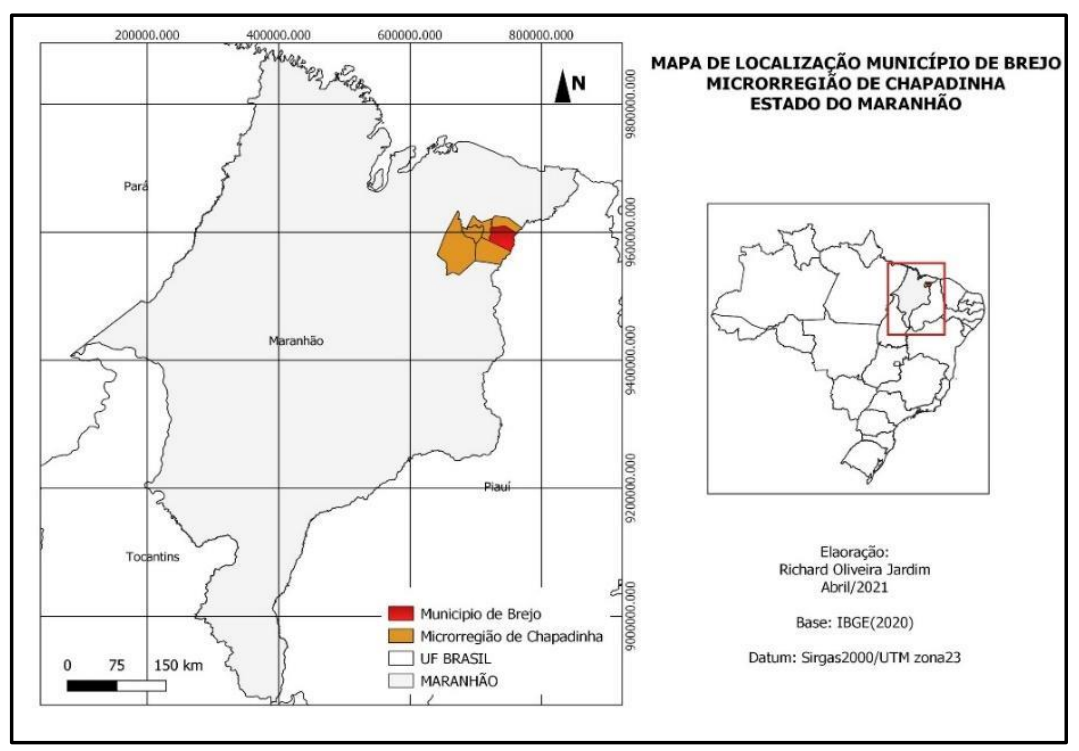

Fonte: elaboração dos autores.

Com uma área de 1.047,628 km², o município de Brejo tem uma população, tal registrada no último censo (2010) pelo Instituto Brasileiro de Geografia e Estatística (IBGE), de 35.124 habitantes.

Este trabalho propõe mostrar, através de dados obtidos de imagens do satélite Landsat5, as transformações ocorridas na cobertura vegetal do município de Brejo, levando em consideração a supressão de mata/floresta entre os municípios da microrregião citada, nos anos de 2003 e 2010. Estas transformações serão analisadas a partir da utilização dos resultados obtidos através do cálculo do Índice de Vegetação por Diferença Normalizada, popularmente conhecida como NDVI - Normalized Difference Vegetation Index.

\section{Fundamentação teórica}

O uso de imagens de satélite tornou-se um meio muito utilizado para gerenciar e diagnosticar o comportamento ou o potencial agrícola de uma determinada região, uma vez que as informações derivadas de imagens orbitais provêm respostas rápidas e seguras, diretamente vinculadas à avaliação, monitoramento e mapeamento eficientes dessas áreas (FIGUEIREDO, 2005). 


\section{Ensaios de Geografia}

Essays of Geography | POSGEO-UFF

Esse processo decorre a partir da utilização do Sensoriamento Remoto. Para melhor esclarecimento de como ocorre, utilizou-se o conceito de sensoriamento proposto por Novo (1998), o qual define que a utilização conjunta de modernos equipamentos sensoriais; equipamento para processamento dos dados; equipamento de transmissão, aeronaves, espaçonaves etc., com o objetivo de estudar as mais diversas manifestações entre as radiações eletromagnéticas e as substâncias componentes do planeta Terra.

Segundo Liou (2002), o processo mais importante responsável pela transferência de energia na atmosfera é a radiação eletromagnética. Essa radiação viaja em forma de onda eletromagnética, que viaja na velocidade de $2,99793 \pm 1 \times 108 \mathrm{~m} \mathrm{seg}-1$ no vácuo e quase a mesma velocidade no ar. Luz visível, raios gama, raios-x, luz ultravioleta, radiação infravermelha, micro-ondas, sinais de televisão, e ondas de rádio constituem o espectro eletromagnético.

Grande parte da luz que chega aos nossos olhos não vem diretamente de sua fonte, mas indiretamente através do processo de espalhamento. Desta maneira, Liou (2002) destaca que enxergamos a luz solar difusa espalhada quando olhamos em nuvens ou para o céu. Terra e água, superfícies e os objetos que nos cercam são visíveis através da luz que eles se dispersam. Para o autor, uma lâmpada elétrica não nos envia luz diretamente a partir do filamento luminoso, mas geralmente brilha com a luz que tenham sido espalhadas pela ampola de vidro, a menos que olhar diretamente para uma fonte de luz, como o sol, uma chama, ou um filamento incandescente com um bulbo claro, vemos à luz que tem sido disperso.

Fontana (2011) corrobora ao citar que na atmosfera, vemos muitos exemplos coloridos do espalhamento gerado por moléculas, os aerossóis e as nuvens, contendo gotículas de água e cristais de gelo. Céu azul, nuvens brancas, e magníficos arco-íris e halos, para citar alguns, são todos fenômenos de óptica produzidos por dispersão.

Segundo Fontana (2011), como o NDVI é calculado utilizando as bandas TM3 (vermelho) com intervalo de comprimento de onda entre 0,63 e 0,69 $\mu \mathrm{m}$ e TM4 (infravermelho) com intervalo de comprimento de onda entre 0,76 e 0,90 $\mu \mathrm{m}$ (Landsat 5 e 7), e em virtude de sua formulação de cálculo, é observado que para a vegetação este 


\section{Ensaios de Geografia}

Essays of Geography | POSGEO-UFF

índice está associado a valores positivos, pois a reflectância no comprimento de onda referente a banda TM4 é maior que a reflectância na banda TM3 (FONTANA, 2011). Assim, para imagens Landsat 5, as bandas correspondentes ao vermelho e ao infravermelho próximo são as bandas 3 e 4 (USGS, 2013).

\section{Índice de Vegetação por Diferença Normalizada - NDVI}

O NDVI capta transformações lineares de bandas espectrais, realçando o sinal da vegetação, minimizando as variações na irradiância solar e os efeitos do substrato do dossel vegetal (JACKSON; HUETE, 1991), geralmente encontrada nas faixas do vermelho (R) e infravermelho próximo (NIR) do espectro eletromagnético.

Segundo Baret et. al (1989), estas duas bandas contêm mais de 90\% da variação da resposta espectral da vegetação. Rouse et al. (1974) propuseram o Índice denominado Normalized Difference Vegetation Index (NDVI) definido pela seguinte equação 1.0:

Figura 2 - Normalized Difference Vegetation Index

$$
N D V I=\frac{(N I R-R e d)}{(N I R+R e d)}
$$

Fonte: elaboração dos autores

em que NIR $=$ Infravermelho próximo $(0,75-0,90 \mu \mathrm{m}) ;$ e, $\operatorname{Red}=$ Vermelho $(0,63$ $-0,70 \mu \mathrm{m})$.

O NDVI é utilizado para identificar a presença de vegetação verde na superfície, permitindo caracterizar sua distribuição espacial e a evolução do seu estado ao longo do tempo, que é determinada a partir das variações das condições climáticas dominantes e analisada a partir de imagens temporais (FOLHES, 2005).

\section{Metodologia}

Como procedimentos metodológicos, realizou-se levantamento e revisão bibliográfica sobre os temas como sensoriamento remoto, índices de vegetação e expansão da fronteira agrícola no estado do Maranhão. 


\section{Ensaios de Geografia} Essays of Geography I POSGEO-UFF

Foram utilizadas imagens digitais do satélite LANDSAT 5 (Land Remote Sensing Satellite), e com datas 08/2003 e 11/2010, adquiridas através do portal do Instituto Nacional de Pesquisas Espaciais (INPE). As imagens foram escolhidas por apresentarem menor incidência de nuvens, o que favoreceu a obtenção e interpretação do NDVI. O referido sensor opera com 7 bandas nas regiões do visível, infravermelho próximo, médio e termal. As bandas 1, 2, 3, 4, 5 e 7 possuem 30 metros de resolução e a banda 6 possui 120 metros, que corresponde à banda do termal. As imagens ainda possuem resolução temporal do satélite de 16 dias.

Conforme exposto anteriormente, o NDVI é calculado a partir de valores de reflectância das bandas referentes ao espectro do vermelho e ao infravermelho próximo. No caso do sensor TM, estas bandas são respectivamente as de número 3 e 4 .

A produção do material cartográfico teve o mosaico como base em três imagens (cenas) do satélite Landsat 5, com câmeras dos sensores Thematic Mapper (TM). A primeira cena com datas de 05/08/2003 e 12/11/2010 com órbita/ponto 219/63; a segunda cena com datas de 11/07/2003 e 15/08/2010 órbita/ponto 220/62; e a cena três com datas de 11/07/2003 e 15/08/2010 órbita/ponto 220/63. Os anos escolhidos para análise correspondem ao período de maior expressividade na produção agrícola da primeira década dos anos dois mil no município em questão.

A escala de medida para avaliar os resultados do NDVI tem a propriedade de variar de -1 a +1 , com o zero indicando valor sem vegetação. Como aponta Acco: “[ ...] A utilização deste índice justifica-se devido a sua contribuição na discriminação de unidades de vegetação, pois o NDVI [...] realça a vegetação na imagem" (ACCO, 2004, p.12). Quanto mais próximo do valor 1 mais vegetação densa.

Os procedimentos adotados para a delimitação das áreas com mudança de cobertura vegetal foram desenvolvidos com o auxílio do software QGis ${ }^{2}$, realizando em três etapas: (i) o pré-processamento, (ii) o processamento sensu stricto, e (iii) a geração dos mapas. No (i) pré-processamento ocorreu a reprojeção das imagens para o hemisfério sul.

\footnotetext{
${ }^{2}$ Quantum GIS (QGIS) é um software voltado para Sistema de Informação Geográfica de código aberto. 


\section{Ensaios de Geografia}

Essays of Geography | POSGEO-UFF

Foram executadas as seguintes operações, para as correções radiométricas, conversão de Números Digitais - ND para Reflectância Aparente, posteriormente para Reflectância de Superfície e Subtração de Objeto Escuro dark object subtraction, empregado por Saha (2005).

Adicionadas as camadas no software Qgis, utilizou-se a "Calculadora Raster" e aplicou-se a equação 1.0. A partir da imagem gerada, aplicou-se uma composição falsa cor para que certos elementos da imagem ficassem realçados. Posteriormente, realizouse o recorte da imagem, utilizando limites municipais em arquivos de extensão shapefile (.shp) fornecidos pelo IBGE em seu site (www.ibge.gov.br). Para obter o recorte da imagem, selecionou-se a opção no menu "Raster", em seguida, em "Extração" e em "Cortador".

Utilizou-se, ainda, das técnicas de contraste para melhor visualização da imagem, permitindo identificar com maior facilidade visual o alvo central da pesquisa, que é a vegetação. Assim, delimitaram-se as áreas com mudança de cobertura através da comparação das imagens correspondentes ao município de Brejo-MA dos anos de 2003 e 2010, obtendo-se em seguida o cálculo do NDVI. Esses anos correspondem aos primeiros sete anos de ascensão da produção agrícola de soja no município.

Após a obtenção dos dados de NDVI foi realizada uma classificação com 4 categorias para diferenciar a classe com maior reflectância. Com a padronização do processamento para as duas cenas foi possível realizar uma comparação dos mapas.

Para cálculo das áreas das classes obtidas, foi necessário utilização da ferramenta r.report no Qgis with Grass 7.8.2, selecionando as camadas raster geradas a partir do NDVI, utilizando a unidade de medida em hectares.

\section{Resultados e Discussões}

Recentemente, as alterações na cobertura vegetal do município de Brejo (MA) vêm sendo realizadas por grandes empreendimentos de empresas rurais no setor da sojicultura, como apontam estudos realizados por Carneiro (2008), Almeida e Mattos Júnior (2016), e dados do IBGE (2015) para produção agrícola municipal. 


\section{Ensaios de Geografia} Essays of Geography | POSGEO-UFF

Para inserção de suas atividades, as empresas retiram grande parte da cobertura vegetal natural para a produção da soja, o que torna agravante o processo de desertificação da área, dadas suas características geofísicas ${ }^{3}$ propícias a este processo. Outro agravante é a diminuição da vegetação nativa, ficando parcial ou totalmente impossibilitadas as atividades de subsistência da agricultura familiar e do extrativismo realizados nas áreas de chapada, local preferencialmente utilizado pelo agronegócio, devido às áreas planificadas.

Entre os anos de 2003 a 2010 a produção de grãos de soja cresceu significativamente, passando de 3.792 mil toneladas a 22.860 mil toneladas nos respectivos anos citados (IBGE, 2015). Este fato possibilitou que o município conquistasse a liderança da produção em relação aos demais municípios que compõem a microrregião.

No intervalo de tempo estabelecido para análise, a área agrícola do município passou de 1.047,5 (mil) hectares para 12.700 (mil) hectares, segundo os dados de Produção Agrícola Municipal do IBGE (2015). Este resultado mostra a diferença de 11.652,5 (mil) hectares, correspondente a um aumento de 1212,41\% de área cultivada.

As atividades voltadas para sojicultura se expandiram no intervalo amostrado (Figura 3), o que também contribuiu para a redução da área com vegetação nativa, como apontam dados de pesquisas realizadas por Almeida e Mattos Júnior (2016) sinalizando que, à medida que a soja avança no município, verifica-se uma diminuição na área destinada a outros cultivos da agricultura camponesa como o arroz e mandioca, responsáveis, sobretudo, pela alimentação dessa população local.

\footnotetext{
${ }^{3}$ Recomenda-se a leitura do texto "Panorama da desertificação no estado do Maranhão", publicado no portal do Ministério do Meio Ambiente, no seguinte endereço eletrônico: <www.mma.gov.br/estruturas/sedr_desertif/_.../panorama_maranhao.doc>. 


\section{Ensaios de Geografia}

Essays of Geography I POSGEO-UFF

Figura 3 - Expansão da produção de soja no município de Brejo (MA)

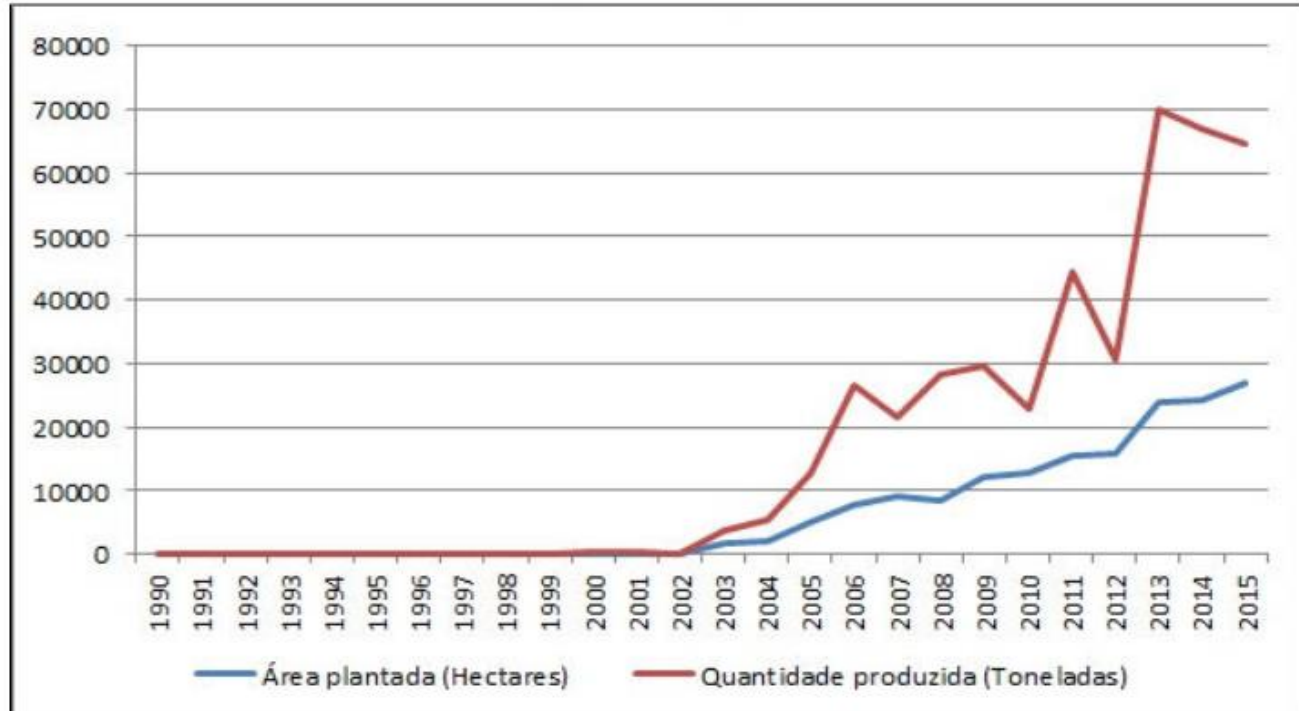

Fonte: IBGE - Produção Agrícola Municipal.

Nos anos de 2004 a 2006, a produtividade e a área plantada com soja no município deram um salto significativo, isto por no último ano ter sido registrada uma produção de 26.611 toneladas (IBGE, 2015).

É possível visualizar esta tendência na Figura 3 quando se observa os números de forma individual da dinâmica da área em hectares referente a três produtos (arroz, mandioca e soja).

De acordo com informações fornecidas pelo IBGE (2015), foi no ano de 2010 que se passou a registrar uma relação inversamente proporcional entre aumento da área de produção de soja e diminuição das destinadas aos produtos como a mandioca e o arroz. Assim, os dados fornecidos pelo instituto revelaram ainda que a soja ocupou, neste ano, no município de Brejo, uma área de 12.700 hectares, enquanto é registrado para os demais produtos aqui analisados 1.120 hectares para a mandioca e 6.540 hectares para o arroz, a soja quase dobrando número de sua área, fato que comprova mais uma vez seu caráter concentrador. 


\section{Ensaios de Geografia}

Essays of Geography I POSGEO-UFF

Figura 4 - Dinâmica da área plantada com arroz, mandioca e soja no município de Brejo (MA) (1990 - 2015).

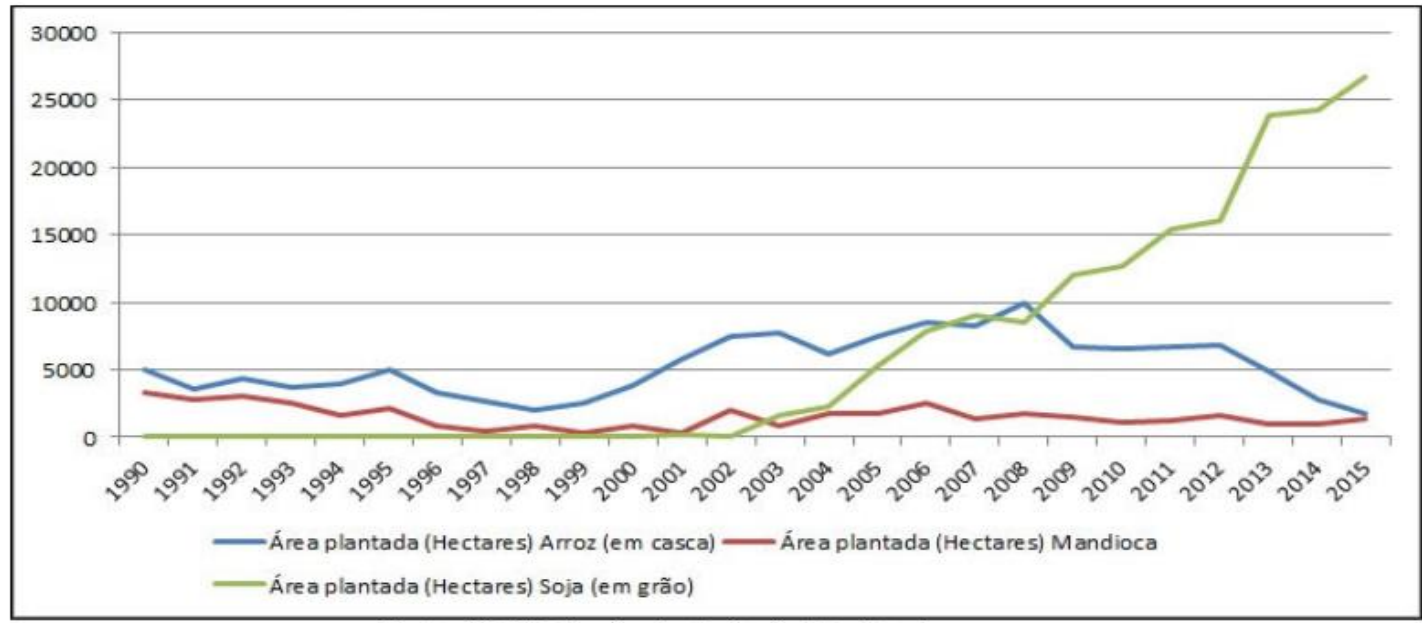

Fonte: IBGE - Produção Agrícola Municipal.

Vale ressaltar, que neste trabalho, não queremos afirmar que apenas a produção da sojicultura é responsável pela mudança na cobertura vegetal do município. Para isto, são necessárias visitas de campo para localizar as áreas específicas de plantação de soja. No entanto, é possível afirmar, a partir dos dados acima, que esta prática desempenha papel fundamental na transformação da vegetação local, aumentando assim áreas de solo exposto, principalmente porque faz parte do período seco na região.

A visualização destes dados pode ser comparada com os resultados do cálculo do NDVI nas imagens de satélite selecionadas, explicadas a seguir (Figuras 5 e 6).

Figura 5 - Imagem Landsat TM5 município de Brejo (MA) (2003). 


\section{Ensaios de Geografia}

\section{Essays of Geography | POSGEO-UFF}

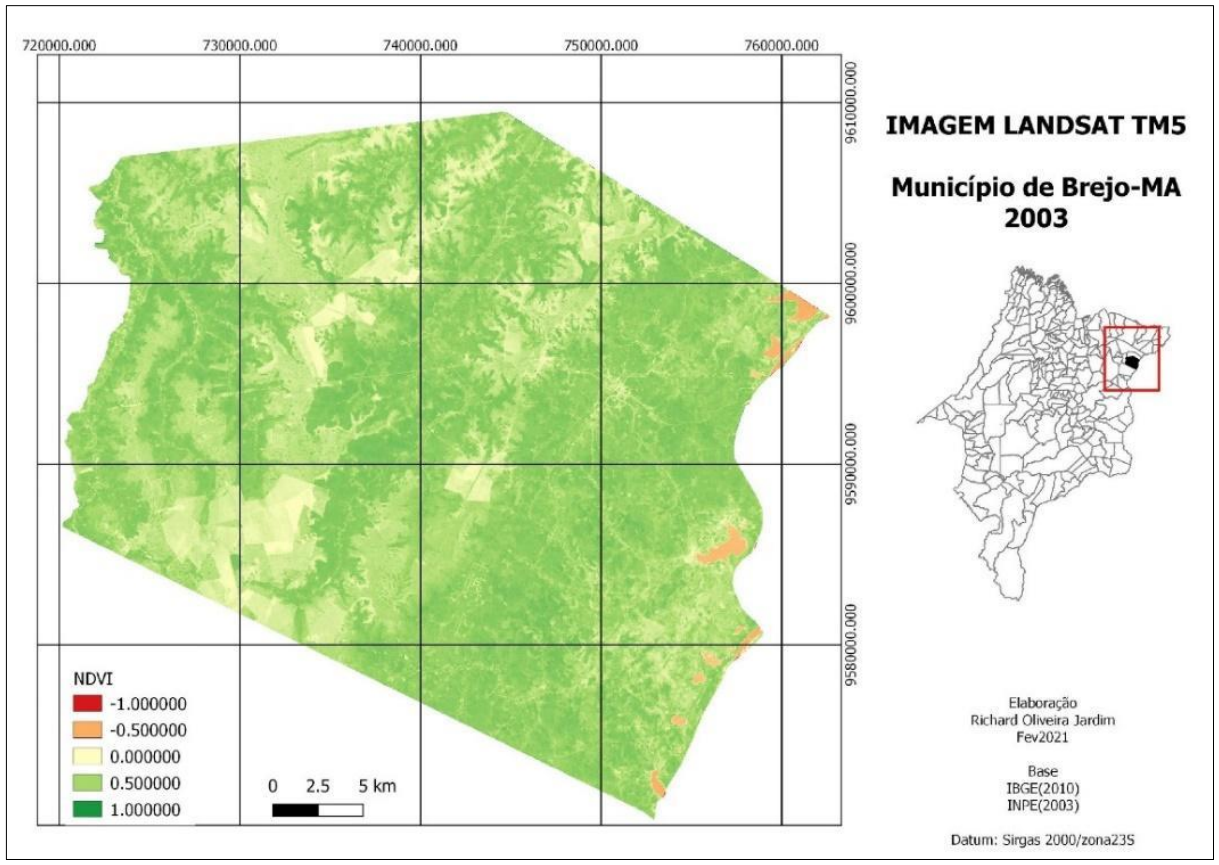

Fonte: elaboração dos autores.

Figura 6 - Imagem Landsat TM5 município de Brejo (MA) (2010).

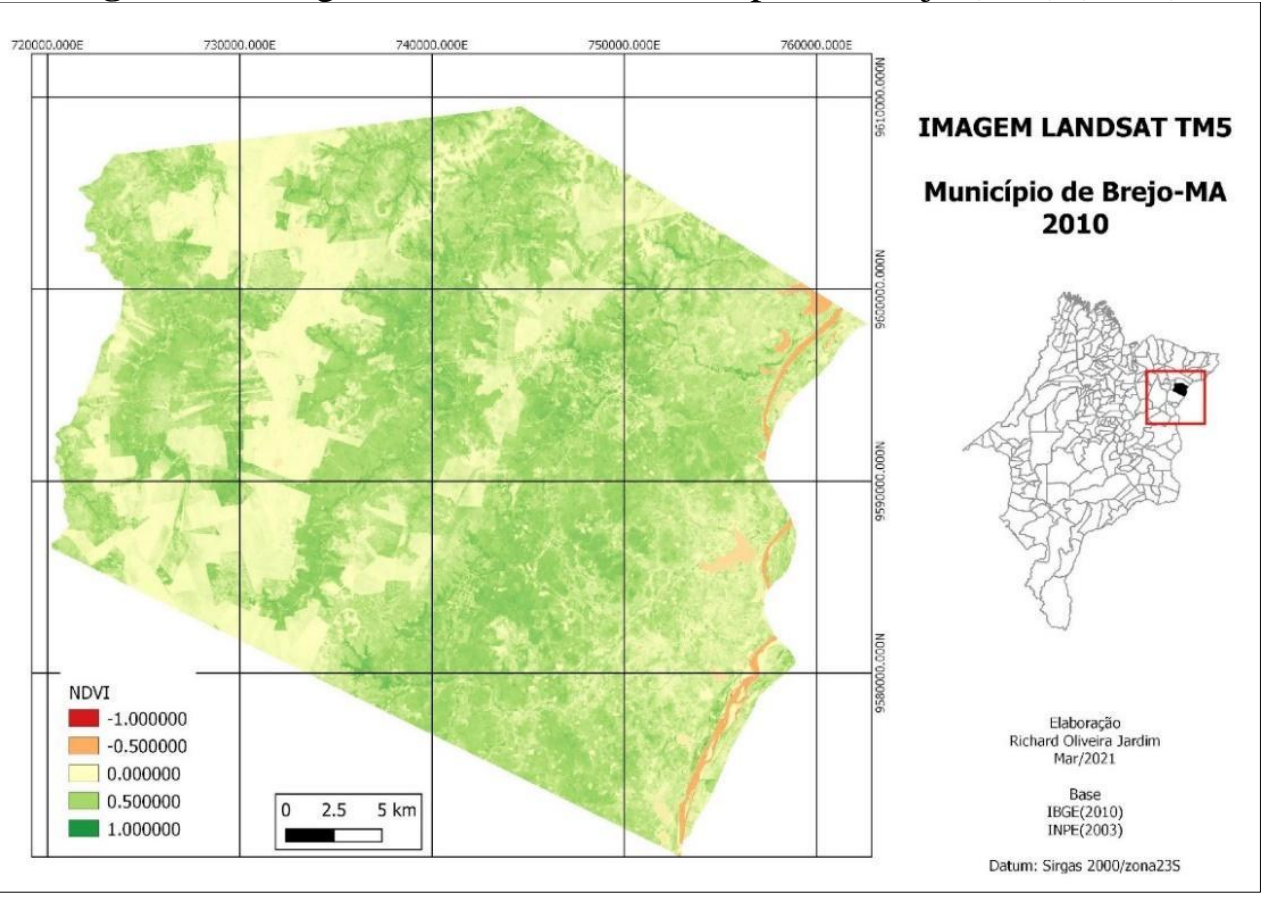

Fonte: elaboração dos autores.

AO CITAR ESTE TRABALHO, UTILIZAR A SEGUINTE REFERÊNCIA:

JARDIM, Richard Oliveira. Mudança da cobertura vegetal do município de Brejo (MA): uma análise a partir do cálculo do Índice de Vegetação por diferença normalizada (NDVI). Revista Ensaios de Geografia. Niterói, vol. 7, nº 14, pp. 147-162, maio-agosto de 2021.

Submissão em: 03/02/2021. Aceito em: 28/04/2021.

ISSN: 2316-8544 


\section{Ensaios de Geografia}

Essays of Geography | POSGEO-UFF

Os valores obtidos a partir das imagens foram classificados da seguinte forma: valores negativos, entre -1 e $-0,5$, indicam a presença de água (entre as cores laranja e vermelho); valores de NDVI, entre -0,6 e 0,09, (cor amarela) indicam teor de vegetação inexistente ou solo exposto; valores, entre 0,1 e 0,4 (verde-claro) indicam teor baixo de vegetação ou vegetação rasteira; e, acima de 0,5 indicam vegetação densa.

Ressalta-se que segundo Brasil (2004) estas vegetações, que fazem parte do cerrado, possuem raízes muito profundas, o que lhes garante a água necessária à sua sobrevivência até mesmo nas épocas mais secas do ano, bem como é caracterizada por uma grande extensão de campos com árvores pouco altas. Assim, o que chamamos de vegetação densa deve ser compreendida como áreas de cerrado.

Ao longo dos anos analisados verificou-se que nos resultados do NDVI ocorreu uma heterogeneidade na área da vegetação, com uma redução significativa nos anos de 2003 e 2010 (Figuras 5 e 6), aumentando a área de solo exposto (em amarelo). No ano de 2003 (Figura 5), houve um destaque para a vegetação que estava preservada na área de estudo correspondendo ao período de início, mas ainda modesto, de produção de soja no município.

Ao analisar as 3 classes intermediárias (laranja, amarelo e verde e claro) da Figura 5, verificou-se uma expressividade da vegetação flutuante das classes de 1 a 0,5 , que podem ser pastagens, revegetação, diferentes usos do solo e mata nativa. Na figura 6 foi possível notar o crescimento significativo de solo exposto, em relação a figura 5, nos resultados com valor próximo ou igual a zero (cor amarela).

Ao analisar a vegetação entre as duas figuras, percebe-se uma diminuição menos acentuada da densa vegetação na porção leste, e uma concentração do desmatamento na porção oeste com altos índices no valor zero (cor amarela).

Os resultados também puderam ser comparados através do total de áreas, em hectares, que compreendem o solo exposto, a vegetação rasteira e a vegetação densa. Para solo exposto, no ano de 2003, a área total compreendia a 2.215,81 e, no ano de 2010 19.819: para vegetação rasteira, no ano de 2003, área total de 38.219 e, no ano de 2010, 


\section{Ensaios de Geografia}

Essays of Geography | POSGEO-UFF

55.578; para vegetação densa, no ano de 2003, a área total era de 63.557 e, no ano de $2010,38.219$.

Devido ao período de estiagem do ano correspondente ao mês das imagens selecionadas para a pesquisa, foi possível avaliar a expansão agrícola na fase de preparação do solo, o que se reflete em uma diferença grande nos índices de reflectância gerados com o cálculo do NDVI. Esses índices podem ser comparados através do resultado de reflectância por valor de pixel, representados pelos histogramas (Figura 7).

Figura 7 - Histogramas de reflectância por valor de pixel entre os anos de 2003 (A) e 2010 (B).

(A)

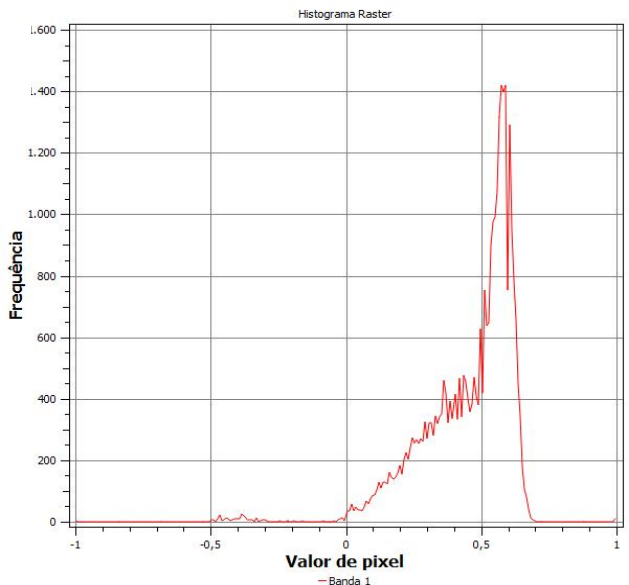

(B)

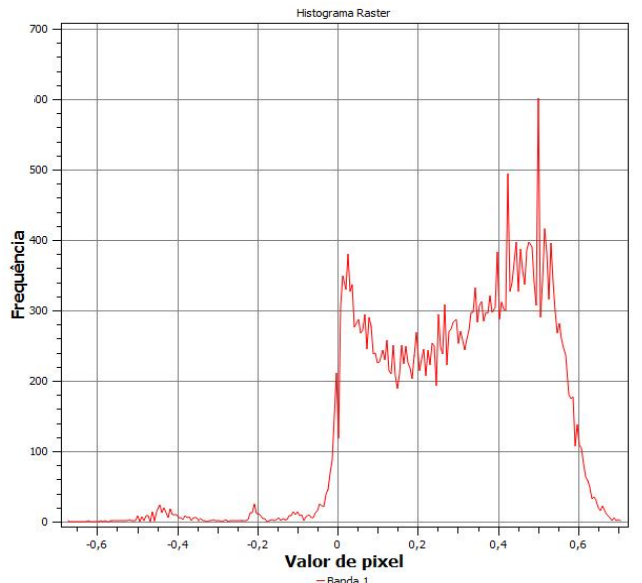

Fonte: arquivo da pesquisa

Os histogramas de reflectância (Figura 7 - A e B) são entendidos na mesma perspectiva que explica Ayoade quando cita que "[...] superfícies secas ou de cores mais claras refletem mais radiação que superfícies úmidas" (AYOADE, 1996, p. 27). Houve crescimento no tamanho da área de solo exposto ou com vegetação de baixo porte, portanto na comparação entre os histogramas, entre zero (0) e um (1), que corresponde à área de vegetação, aponta o índice de reflectância maior no ano de 2010 (B) em relação a 2003 (A).

A mudança entre os valores dos histogramas pode ser compreendida quando analisamos os dados por intervalos. A frequência com que aparecem os valores dos pixels 


\section{Ensaios de Geografia}

Essays of Geography | POSGEO-UFF

entre o intervalo 0,30 e 0,60, figura 7A são maiores, indicando presença de vegetação. Nesta mesma figura, a frequência de reflectância presente próximo ao valor zero é pequena. Já na figura 7B, percebe-se que a frequência no índice de reflectância aumentou significativamente entre os valores próximo a zero, o que indica crescimento na área de solo exposto, ou seja, áreas que em 2003 possuíam vegetação e foram desmatadas ao longo dos sete anos até o ano 2010.

\section{Considerações Finais}

A técnica do cálculo do NDVI foi de extrema relevância na identificação de áreas com e sem cobertura vegetal. Ao utilizar a técnica foi possível verificar a resposta de reflectância da energia solar, o que ocorre devido à produção fotossintética das formações vegetais.

Levando-se em consideração a dinâmica do agronegócio do município de Brejo (MA), é primordial o seu monitoramento. Assim, o emprego da análise multitemporal passa a ser uma importante ferramenta para subsidiar o planejamento e a gestão ambiental.

A análise por meio da técnica de sensoriamento remoto utilizando séries temporais de imagens de satélite Landsat TM5 selecionadas apontou que há uma expansão considerável da sojicultura no município de Brejo (MA), comparado aos dados fornecidos pelo IBGE. Desta maneira, o software possibilitou a análise da mudança na cobertura vegetal na área selecionada para o estudo. A análise pode ser realizada tanto através do meio visual quanto por dados quantitativos, duas de variadas formas de análise espacial por resultados de geoprocessamento preconizadas por Câmara et al. (2004).

Sugere-se ao poder público e órgãos competentes a fiscalização ambiental, através dos dispositivos legais na legislação ambiental, garantindo um meio ambiente equilibrado para todos, não só através da fiscalização das diversas atividades praticadas na cidade como também mediante a promoção da educação ambiental para a população. 


\section{Ensaios de Geografia}

Essays of Geography | POSGEO-UFF

\section{Referências}

ACCO, M. Modelagem de dados do satélite ikonos II para Estimativa de micronutrientes na floresta ombrófila mista montana. Dissertação de Mestrado. Curitiba: UFPR, 2004. Disponível em: <http://dspace.c3sl.ufpr.br/dspace/bitstream/handle/1884/34230/R\%20-\%20D\%20\%20MONICA\%20ACCO.pdf?sequence=1>. Acesso em: 10 abr. 2015.

ALMEIDA, J. G.; MATTOS JUNIOR, J. S. de. A DINÂMICA DA PRODUÇÃO DE SOJA NO MUNICÍPIO DE BREJO (MA) E SEUS EFEITOS NA PRODUÇÃO AGRÍCOLA CAMPONESA. In: CAMPO-TERRITÓRIO: revista de geografia agrária, v. 11, n. 24, p. 374-399, 2016.

AYOADE, J. O. Introdução à climatologia para os trópicos. $4^{\mathrm{a}}$ ed. Rio de Janeiro: Bertrand Brasil, 1996.

BARET, F.; GUYOT, G.; MAJOR, D. TSAVI: A vegetation index which minimizes soil brightness effects on LAI or PAR estimation. In: Canadian Symposium on Remote Sensing, 12., 1989, Vancouver. Ottawa: Canadian Remote Sensing Society, p.1195-1197, 1989.

BRASIL. Secretaria de Estado de Infraestrutura e Obras / Secretaria de Meio Ambiente e Recursos Hídricos. Biodiversidade, vida no Cerrado. Brasília, 2004. Disponível em < ibram.df.gov.br>. Acesso em: 6 abr. 2021.

CÂMARA, G. et al. Análises espaciais e geoprocessamento. DRUCK, S.; CARVALHO, M.S.; CÂMARA, G.; MONTEIRO, A. V. M. (Eds.) Análise Espacial de Dados Geográficos. Brasília: EMBRAPA, 2004.

CARNEIRO, M. S.; VIEIRA, A. S.; BARROSO, A. R.; SILVA JÚNIOR, A. F. A expansão e os impactos da soja no Maranhão. In: SCHLESINGER, S.; NUNES, S. P.; CARNEIRO, M. S. (Orgs.). Agricultura familiar da soja na região sul e o monocultivo no Maranhão: duas faces do cultivo da soja no Brasil. Rio de Janeiro: FASE, p. 89-146, 2008.

FIGUEIREDO, Divino. Conceitos básicos de sensoriamento remoto. In: Conabweb, $2005 . \quad$ Disponível em <http://www.conab.gov.br/conabweb/download/SIGABRASIL/manuais/conceitos_sm.p df>. Acesso em: 10 abr. 2015. 
FOLHES, M. T. Uma aplicação da banda termal do TM/Landsat-5 no gerenciamento dos recursos hídricos. In: Anais do Simpósio Brasileiro de Sensoriamento Remoto, v. 12, 2005, Goiânia. São José dos Campos: INPE, p. 3009-3016, 2005.

FONTANA, D. C. Comportamento espectral da vegetação. Rio Grande do Sul: UFRGS, 2011. 122 slides, color.

INSTITUTO BRASILEIRO DE GEOGRAFIA E ESTATÍSTICA (2021). Produção Agrícola Municipal de 1990 a 2015. Disponível em: <www.ibge.gov.br>. Acesso em 28 mar. 2021.

JACKSON, R. D.; HUETE, A. R. Interpreting vegetation indices. Preventive Veterinary Medicine, v.11, n.3-4, p.185-200, 1991.

LOURENÇO, R.W.; LANDIM, P.M.B. Estudo da variabilidade do índice de vegetação por diferença normatizada "NDVI" utilizando krigagem indicativa. HOLOS Environment, v.4, n.1, p. 38-55, 2004.

LIOU, K. N. An Introduction to Atmospheric Radiation. $2^{\text {nd }}$ edition. California: International Geophysics Series, v. 84, 2002.

NOVO, E. M. L. de M. Sensoriamento Remoto: princípios e aplicações. $2^{a}$ ed. São Paulo: Edgard Blücher, 1998.

OLIVEIRA, T. H.; MACHADO, C. C. C.; SANTOS, J. S.; GALVÍNCIO, J. D.; PIMENTEL, R. M. M.; SILVA, B. B. Índice de umidade (NDWI) e Análise espaçotemporal do albedo da superfície da Bacia Hidrográfica do Rio Moxotó - PE. Revista Brasileira de Geografia Física, UFPE, v.3, p. 55-69, 2010.

ROUSE, J. W.; HAASM, R. H.; SCHELL, J.A.; DEERING, D.W.; HARLAN, J. C. Monitoring the vernal advancement of retrogradation of natural vegetation. Greenbelt: NASA/GSFC, 1974.

SAHA, A. K. et al. 2005. Land Cover Classification Using IRS LISS III Image and DEM in a Rugged Terrain: A Case Study in Himalayas. Disponível em: <http://www.geocarto.com.hk/cgibin/pages1/june05/33_Saha.pdf>. Acesso em: 20 abr. 2013. 